\title{
Steuerlich privilegiert anlegen
}

\section{Nutzen Sie die Vorteile von Einmaleinlagen}

Möchten Sie eine renditeorientierte Anlage mit einem 100prozentigen Kapitalschutz und steuerlichen Vorteilen? AXA CAPITAL COMFORT, von uns geprüft und empfohlen, erfüllt Ihre Wünsche.

Bei AXA CAPITAL COMFORT wird Ihr Kapital in den aktienorientierten Fonds BCV Dynamic Floor Fund World Expoequity REP (CHF) investiert. Beim Vertragsablauf wird der Wert Ihrer Fondsanteile, jedoch mindestens die im voraus festgelegte garantierte Summe ausbezahlt. Sie profitieren so von einer höheren Renditemöglichkeit, ohne auf die hervorragende finanzielle Sicherheit Ihrer Anlage verzichten zu müssen. Weiter fallen während der gesamten Laufzeit keinerlei Kosten wie Depotgebühren, Courtagen oder Vermögensverwaltungskosten an.

Entscheiden Sie sich bis am 30. Juni 2006 zum Abschluss eines AXA-CAPITAL-COMFORT-Vertrages, wird Ihnen zudem die Stempelsteuer von $2,5 \%$ geschenkt.

Berechnungsbeispiel: Mann, Alter 52, Einmaleinlage CHF 100 000.-

Dauer 10 Jahre Dauer 12 Jahre

Garantierte Mindestauszahlung im Todesfall:

CHF 131 104.- CHF 139077.-

Garantierte Mindestauszahlung bei Versicherungsablauf:

CHF 100000.- CHF $100000 .-$

Steuerfreie Auszahlung bei einer Fondsrendite von $5 \%$ :

CHF 152709.- CHF $167267 .-$

Benötigte Rendite einer steuerpflichtigen Anlage (Grenzsteuer 35\%):

$6,65 \% \quad 6,74 \%$

Ihr Geschenk während dieses Sonderangebots:

CHF 2500.- CHF 2500.-

Profitieren Sie jetzt und bestellen Sie Ihre persönliche Offerte.

Ihre Bedürfnisse stehen bei uns im Mittelpunkt. Mit unserem Namen garantieren wir Ihnen die Betreuung durch professionelle Berater mit langjähriger Erfahrung im Versicherungs- und/oder Bankenbereich. Dank unserer Unabhängigkeit können wir Ihnen das für Sie am besten geeignete Produkt anbieten.

\section{Antworttalon}

Vorname / Name

Adresse

PLZ / Ort

Geburtsdatum

Telefon Privat/Geschäft

Beste Zeit für einen Anruf

Ich wünsche eine persönliche Offerte.

Ich interessiere mich für folgende Produkte:

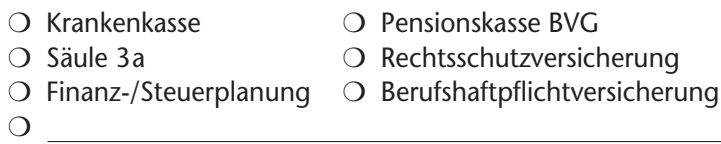

